\title{
Efficiency and Equity in the Spatial Planning of Primary Schools
}

\author{
Jan Wolf, GOVCOPP, University of Aveiro, Portugal \\ iD https://orcid.org/0000-0002-8701-7117 \\ Fillipe Feitosa, GOVCOPP, University of Aveiro, Portugal \\ João Lourenço Marques, GOVCOPP, University of Aveiro, Portugal \\ iD https://orcid.org/0000-0003-0472-2767
}

\begin{abstract}
The shrinking populations of many regions in Portugal have led to a debate on the criteria which should guide the restructuring of public services at the local scale, and namely how to balance raising per capita costs with guaranteeing equity in accessibility. This article contributes to this debate by analyzing the spatial distribution of primary schools in the municipality of Vagos. It is based on a linear programming approach to optimize the resources needed for the operation and installation of school facilities and the level of accessibility that is provided. The simulated configurations are used as benchmarks for the actual spatial distribution of schools, identifying how it could be made more efficient or equitable and the criteria which have been prioritized in recent school planning policies. This allowed to conclude that, in the analyzed context, changes to the spatial distribution of schools have been made with significant equity concerns and that, while it would be possible to decrease costs through further consolidation, this would pose significant equity challenges.
\end{abstract}

\section{KEYWORDS}

Capacitated Facility Location Problem, Efficiency, Linear Programming, P-Median Problem, Portugal, Primary Schools, School Consolidation, Spatial Equity, Spatial Planning

\section{INTRODUCTION}

The declining populations of many regions in Europe have led to a significant restructuring of services of general interest which, in many cases, meant concentrating them in fewer locations (Lang, 2012, p. 1749). This raised a discussion about the policy goals that should be at the core of these reconfigurations and, namely, how to balance the increasing per capita costs of these services with the need to guarantee minimum standards (Wiechmann \& Pallagst, 2012). In other words, the shrinking number of users often imposes difficult policy decisions on whether to maximize equity in the accessibility to services, accepting that this implies increasing costs, or to maximize efficiency, decreasing service provision. Efficiency and equity can, in this sense, be considered elementary dimensions to assess public policies. But, while providing a useful framework (Bellinger, 2007; Le 
Grand, 1990), this dichotomy also raises important issues. Kunzmann (1998), for example, notes that spatial equity can mean "equal access to basic public facilities, measured in distances" (p. 103), but can also include the choices that are available and the way they relate to social equity. And, if spatial equity is understood as "justice with respect to location" (Morrill \& Symons, 1977, p. 217), this stresses the importance of different theories of justice to understand differences in the spatial accessibility to amenities. Efficiency, on its turn, is generally concerned with minimizing the means necessary to achieve a given policy goal, having a more straightforward definition. However, this concept also raises questions regarding the distinction between means and goals, as well as the way in which the costs and benefits people draw from a given policy are considered (Bromley, 1990).

A further challenge is to translate these concepts into concrete measures to assess spatial layouts and to aid planning policy decisions. Technological development has, in this regard, created new opportunities for decision support systems, through a range of solutions based on optimized computational processing or data analysis. This has helped to establish a new contemporary planning praxis (Silva, 2010), increasingly concerned with incorporating tools to aid planning decisions (geographic information systems or algorithms) or to implement collaborative approaches (Machado \& Azevedo, 2020; Somarakis \& Stratigea, 2019; Wolf, Borges, Marques, \& Castro, 2019).

This article contributes to this field by analyzing the spatial distribution of primary schools of the municipality of Vagos, in Portugal, while trying to find answers to a question raised when working with the municipality to devise a local school planning instrument (the so called school charts): How to adapt the distribution of primary schools to the decreasing number of students? For this analysis, it is important to take into consideration that primary schools in Portugal administer the first four years of formal education, corresponding to the first level of the International Standard Classification of Education (ISCED 2011), while municipalities are the second lowest tier of local government and are responsible for planning school facilities, but considering central government regulations and guidelines.

This article adopts an ICT based approach to apply abstract concept - efficiency and equity - to the assessment of concrete spatial layouts, namely the costs and accessibility provided by different distributions of primary schools. In fact, the planning of primary schools is a good subject to understand spatial efficiency and equity: While central government guidelines tend to value the economies of scale associated with concentrating students in fewer facilities, at the local scale school closures are often perceived as an existential threat, affecting the "health of a community" (Kearns et al., 2009), its self-image, or social capital (Autti \& Hyry-Beihammer, 2014). In Portugal a "rationalizing" goal was, namely, assumed by the government regulation of 2010 (Resolução do Conselho de Ministros n. ${ }^{\circ} 44 / 2010,2010$ ), which established that the minimum number for maintaining a primary school is 21 students, while also valuing the availability of amenities or the distance to other schools. But these government guidelines are not simply implemented at the local scale, since municipalities have an active role in constructing, maintaining, and planning primary school facilities. The planning of primary schools in Portugal can, in this sense, by understood as a multi-level governance system, where local forms of coordination interact with institutional regulation at the macro level to define the policies to be followed (Barroso, 2013). According to Cordeiro and Martins (2012) and Cordeiro, Martins, and Ferreira (2014), three types of strategies can be identified as possible outcome of this arrangement: "reconfiguration by decree", which implies a close alignment with national criteria; "reconfiguration by conciliation", where these criteria are harmonized with local ones; and "communitarian reconfiguration", where the national criteria are largely ignored and the planning outcomes depend on bargaining between local and central state agents. The degree to which the restructuring of primary schools is incorporating efficiency goals, through the concentration of primary schools, or incorporates equity concerns, maximizing accessibility, is, therefore, an interesting planning question.

For analyzing the way in which efficiency and equity goals can be incorporated in school planning at the local scale, this article compares the real spatial distribution of the municipality's primary 
schools to hypothetical layouts that prioritize efficiency or equity in accessibility. These layouts are obtained through a standard linear programming approach, to model the trade-offs between the costs of a given spatial distribution of schools and the levels of accessibility which they provide. This allows to identify the criteria which have been prioritized in the recent changes made to primary schools in shrinking territories and it also illustrates the way in which modeling tools, by generating hypothetical spatial layouts which maximize different policy goals, can be useful to support planning decisions.

The next section of this article briefly discusses the concepts of efficiency and equity in public policy focusing, in particular, on utility-based perspectives regarding efficiency, and the normative theories of justice of Amartya Sen and Rawls regarding equity, given their fundamental contributions to the discussion of the central concept that informs spatial equity - justice. Afterwards, data and methodology are presented, followed by a discussion of the main outcomes. The last section discusses the article's main findings, limitations, policy relevance, and future research directions.

\section{EFFICIENCY AND EQUITY IN PUBLIC POLICY}

According to economist William Bellinger (2007) and public policy analyst Le Grand (1990), equity and efficiency are the two fundamental dimensions to assess any public policy, even if the first author also refers the practical implementation and the second author refers individual liberty. But there are many possible understandings of efficiency and equity which, according to different philosophical assumptions, differ on crucial aspects such as: What is the just outcome of a public policy? Should it refer to the outcomes or to the process? How can it be measured?

More than providing a mundane discussion, different answers to these questions lead to fundamentally different policies and, also, policy processes. In the planning field it has, for example, been noted that there is an excessive focus on procedural aspects of policy design, assuming that inclusive, transparent, and accountable processes will automatically yield just outcomes (Fainstein, 2009). This has often led to neglecting the way in which planning decisions transform the real world (Wolf, Nogueira, \& Borges, 2020) and the very practical advantages and disadvantages of a given spatial policy.

Empirical analyses of efficiency and equity in the accessiblity to services, on the contrary, tend to provide practical understandings of the criteria that can be used to assess these principles. But they often settle on (explicit or implicit) definitions, without discussing the broader implications of these concepts. Examples of this king of approach can be found in the analysis of equity in the accessibility to public parks (Chang \& Liao, 2011), to different public facilities (Tsou, Hung, \& Chang, 2005), sport and educational facilities (Taleai, Sliuzas, \& Flacke, 2014), or the efficiency-equality trade-off (Pinho \& Botelho, 2018). And authors that do frame these concepts with the broader discussion in the political philosophy tend to focus on the procedural dimensions of planning policies (Knudsen et al., 2015) or planning discourse (Nylund, 2014).

But integrating a broader discussion of these concept into the assessment of spatial planning solutions provides an interesting perspective, as shown in the work of Frenkel and Israel (2018), which combines Amartya Sen's capability approach and Bourdieu's forms of capital to measure inequality. In service planning, it namely allows to, more consciously, understand the implications of prioritizing a given policy goal in the spatial distribution of these services and to assess the unequal levels of accessibility that are provided.

\section{Efficiency}

For Bellinger (2007), efficiency is the dimension for policy assessment that has the most consolidated theoretical and conceptual framework, and can be understood as an optimum allocation of resources for achieving a given goal. Much of the analysis of efficiency in public policy is based in economic theory where it tends to be understood as an "objective truth rule", which allows to present an outcome 
as a "good thing" based on the scientific objectivity in the way in which this outcome is assessed (Bromley, 1990, p. 87).

According to this perspective, efficiency can be measured by aggregating the utility of individual agents who aim at maximizing it through rational choices. The advantage of this approach is that it establishes a framework to evaluate all human actions according to a single measure - even altruistic behaviour can be considered a mean for increasing individual utility, in the form of a better image of oneself, or the satisfaction drawn from helping (Jordan, 2008; Sen, 2009). The efficiency of a given social setting is, according to this framework, achieved if it is not possible to increase the utility of one agent without decreasing the utility of another one, reaching a Pareto optimum.

In real life, there are many obstacles to achieving Pareto efficiency, related to environmental risks, technological development, or the progressive integration of different phenomena and the complex network of externalities this implies (Just, Hueth, \& Schmitz, 2004). Even from a merely utilitarian, efficiency-based, perspective, these situations can justify the implementation of public policies. If, for example, an activity generates costs to third parties which exceed the utility of the agent, this leads to situations where a public body can intervene, increasing the overall utility and, thus, the efficiency, from a social cost perspective.

However, the definition of any public policy implies choosing between different options, according to the preferences of the majority of the stakeholders. These preferences can be understood as the value which is ascribed to the outcomes of a given policy or to alternative courses of action (Oppenheimer, 2012, p. 16). But passing from individual to collective preferences raises important issues. As proven by Arrow (1950), there are patterns in individual preferences which cannot be consistently translated into collective choices, thus making it impossible to find absolutely coherent ways to assess if a policy improves the status quo and, therefore, if it is efficient. Other important issues concern dealing with decreasing marginal utilities (Bellinger, 2007) or finding the value of non-market goods (Alberini, 1995; Arrow et al., 1993). Also, as noted by Bromley (1990), the definition of efficiency as the relation between ends and means implies a clear distinction between them. One way to do this is to understand the ends as something to which individuals give intrinsic value and the means as those things that allow individuals to obtain them. But this implies some assumptions about what the average individual values, and therefore cannot be established without some external reference.

In short, while the ultimate goal of increasing efficiency in public policy by maximizing well-being can seem rather consensual, the way to define, or measure, this well-being is far from straightforward, highlighting the importance of incorporating broader conceptions of justice into the assessment of public policies.

\section{Equity}

According to Amartya Sen (1992, p. 12; 2009, pp. 291-292) all normative theories of justice assume some ideal of equality. Utilitarianism assumes, for example, that people's utility is equally important, while libertarianism assumes equality regarding a whole class of rights and liberties, from selfownership to private property. The real question is, thus, "equality of what" (Sen, 2009, p. 293; Sen, 1992, p. 27), stressing the importance of different theories of justice to allow a more thorough understanding of equality.

One of the most important theories of justice was developed by Rawls (1971; 1981), who proposes a systematic alternative to utilitarianism, which he considers insufficient to understand the basic rights and liberties of free and equal citizens. His conception of justice is based on a social contract that is established from a neutral position, and where the just principles that should guide society are defined impartially, through a veil of ignorance regarding personal, social, and historical conditions.

The basic principles established by Rawls in A Theory of Justice (1971, p. 53), and which were later reviewed in The Basic Liberties and Their Priority (1981, p. 5) are: 
1. Each person has an equal right to a fully adequate scheme of equal basic liberties which is compatible with a similar scheme of liberties for all.

2. Social and economic inequalities are to satisfy two conditions. First, they must be attached to offices and positions open to all under conditions of fair equality of opportunity; and second, they must be to the greatest benefit of the least advantaged members of society.

But this conception makes it necessary to define the basic goods to which these principles apply to. According to Rawls, the basic goods should be those that allow the exercise of one's moral powers and to lead a complete life (Rawls, 1981, p. 9). They include: basic liberties; freedom of movement and occupation; powers and privileges from the exercise of position of responsibility; income and wealth; and the social conditions for self-respect.

Compared to narrower, utilitarian, approaches, Rawls' principles provide a more comprehensive understanding of justice in social settings. It implies that mechanisms that decrease inequality should not be understood as a compromise with economic liberties, but instead form the core of a broader conception of freedom: economic freedom is necessary because it makes people responsible for their choices; but economic freedom can be limited so that it doesn't discriminate people for discretionary circumstances and to counter the restrictions to liberty which come with extreme forms of inequality (Kymlicka, 2002).

Another frequently considered understanding of equity is based on Amartya Sen's idea of justice. For Sen, Rawls' theory has some shortcomings, namely the choice of a set of definite principles of justice from an initial position. Therefore, this choice cannot be made in an unambiguous manner, given that it is possible to identify different unbiased principles, based on different understandings of justice. Another important limitation is that a focus on the availability of primary goods does not account for the significant variations in the capacity to translate the availability into actual advantage. There are several contingencies which influence this capacity: individual heterogeneity; diversity in physical environments; variations in the social environment (public health, crime, etc.); relational perspectives (the resources necessary for a dignified life, for example, differ between societies). This means that the justice of a social setting should be assessed according to capabilities, meaning the capacity and possibility to convert a given primary good into desired actions or, in other words, the "substantive opportunity" which is provided by a given good to a given individual (Sen, 2009, p. 295).

Sen's approach is further interesting because it is not only concerned with the outcomes, with the consequences of a given state of affairs, but also with the number of options that are available and with the freedom to choose between them. This leads to the establishment of four different concepts that translate different types of advantage: well-being achievement; agency achievement; well-being freedom; agency freedom (Sen 2009, p. 287). For public policies, the distinction between them is important since some goals are, from a collective point of view, more desirable than others. It is, for example, socially desirable to provide people with the opportunity to lead a dignified life (wellbeing freedom) but is not generally accepted to force people to do so (well-being achievement). But, although identifying general principles and concepts which are useful for thinking about justice in public policies, Sen points out that applying these principles implies a framework for public reasoning to make a rational judgement on policy options: "The capability perspective does point to the central relevance of the inequality of capabilities in the assessment of social disparities, but it does not, on its own, propose any specific formula for policy decisions" (Sen, 2009, p. 232).

\section{THE SPATIAL DISTRIBUTION OF PRIMARY SCHOOLS IN THE MUNICIPALITY OF VAGOS}

Applying the broad principles discussed in the previous point to the planning of a fundamental service, such as primary schools, is challenging. This type of facility has been shown to impact community life at many different levels. The most immediate impact that their presence or absence has on a 
community is on student achievement. Transferring students to larger, better equipped, facilities can, for example, expose them to higher quality peer groups and teachers, but can also disrupt peer and teacher networks, and imply longer travel times (Brummet, 2014). And schools have also been positively related to socioeconomic indicators (Lyson, 2002), housing prices (Brunner et al., 2012) and are considered to play an important role in communities' self-image or social capital (Autti \& Hyry-Beihammer, 2014). But keeping schools open in small communities also leads to inefficiencies, given the economies of scale in capital costs, operational costs, capacity utilization rate, or staff costs that tend to be gained from increasing school size (Ares Abalde, 2014; Chakraborty et al., 2000; Cohn, 1968).

However, even when considering only the spatial aspect of inequality, not taking into consideration the way this accessibility is related to socioeconomic variables, equity and efficiency can be analyzed from different perspectives. Is it, for example, more equitable to minimize users' average accessibility, or to guarantee that no user is above a certain threshold? Or at what degree of concentration do transportation costs outweigh the economies of scale associated with having fewer schools?

To discuss these issues, this article analyzes the spatial layout of the primary schools of the municipality of Vagos. In this analysis, spatial equity is understood as the goal of maximizing accessibility and efficiency is understood as the goal of minimizing costs. The methodology is based on applying a standard linear programming approach, optimizing the resources for operating and installing school facilities, and the distance covered by the students to the closest school. According to Le Grand (1990), efficiency and equity are often understood as two conflicting goals, where increasing one means decreasing the other. However, as this author argues, this would mean that efficiency is a goal in the same way as equity, and thus conflict with the notions of efficiency as applying to the relation between goals and means. It can, for example, be assumed that if the goal of a given policy is to maximize equity, then the solution that does so with the minimum cost is, to the same degree, equitable and efficient. But it is possible to have a different understanding of these concepts for public policy: maximizing efficiency can be understood as the goal to reduce the costs of providing a given service; maximizing equity can be understood as raising the standards at which the services is made available to guarantee that everybody gets a fair access, even if this means increasing costs. This perspective is shown schematically in Figure 1.

\section{The General Context}

The analysis benefited from the author's cooperation with this municipality to aid the planning of school facilities for the medium term, and namely the ten years for which the local planning instruments (the school charts) are meant to be used before being revised (as mandated by the Decreto-Lei n. $\left.{ }^{\circ} 21 / 2019\right)$. In particular, cooperating with the municipality meant analyzing different possible

Figure 1. Efficiency vs. Equity

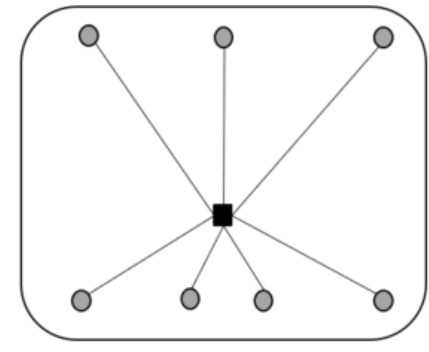

Maximum efficiency

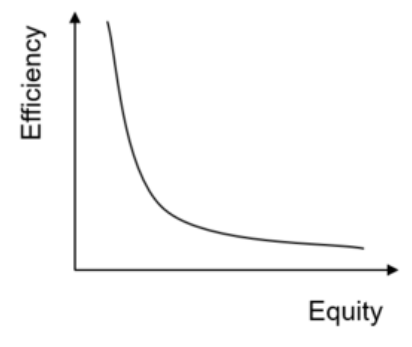

Equity

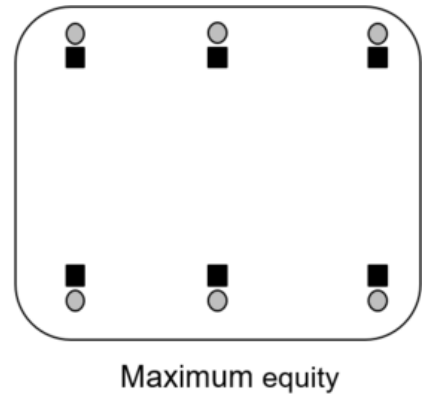

Maximum equity

Students

School 

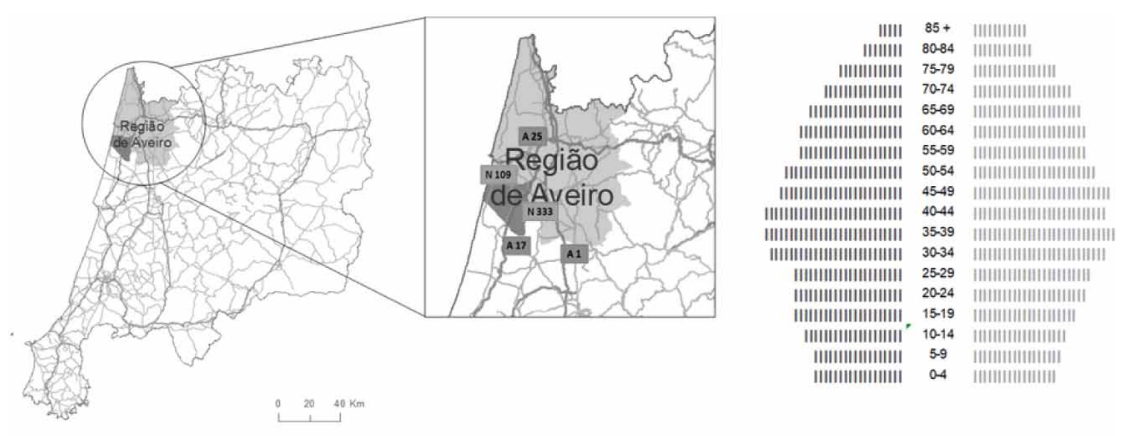

Sources: (Vagos Municipality's Schooling Chart, 2019 \& National Statistical Institute)

distributions of the schools throughout the territory, and their implication regarding the distance students would need to travel, and also having access to data and interesting inputs regarding the way these problems can be formulated.

The socioeconomic and territorial context of the municipality of Vagos is generally favorable, being located in a coastal region in Portugal (see Figure 2), and having a population density above the national average (140 residents per square $\mathrm{km}$ in the 2011 Census, compared to the 115 of the whole country). It is close to major transports infrastructures, such as a port, the most important railway line (the Linha do Norte), and the most important highway (the A1), and is part of the dynamic and very industrialized Aveiro Region, where it tends to be considered a secondary urban area (CCDRC, 2013). In the last years, this municipality has been witnessing declining employment numbers, but this decline has been below the national average, and it also has a relatively low unemployment rate (Câmara Municipal de Vagos, 2015).

Notwithstanding the favorable context, the municipality has been witnessing a significant ageing and population decline, leading to a drop in student enrollment and to changes to the spatial distribution of schools. As can be seen in Figure 3, the main trend is a decrease in the number of primary schools and the concentration of the students in fewer, larger, facilities. The closure of small primary schools in this municipality has already led to a significant increase in the average size of the primary schools while also raising the occupancy rate of the schools. In fact, between 2005 and 2015 the average school size increased from around 40 students to around 80, while the occupancy rates rose from $70 \%$ to more than $90 \%$ (according to data provided by the municipality).

Adding to the decline that already occurred in the number of students, the municipality is currently witnessing what some author call a "negative momentum of demographic growth" (Davoudi et al., 2010), as becomes clear from the age structure presented in Figure 2. The shrinking and ageing populations will imply further school closures in the medium term and raises the question of how much concentration is desirable, from an efficiency and equity perspective. In fact, the challenge further school consolidation poses to local communities, as well as the need to provide equitable levels of accessibility throughout the territory, was a major concern expressed by the local policymakers involved in the municipality's school planning process. This challenge can also be understood in the broader context of school consolidations which have occurred in many European regions over the last decades. Analyses of this phenomenon can be found in: Barakat (2015), regarding the school consolidation in Saxony; Autti and Hyry-Beihammer (2014), regarding school closures in rural Finland; Slee and Miller (2015) regarding school consolidation in Scotland; Egelund and Laustsen (2006) regarding the impact of school closures in Denmark; or Elshof, Haartsen and Mulder (2015) regarding the impact of school absence and closure on migration in the Netherlands. In Portugal, 
Figure 3. Recent changes in the number of students enrolled in primary education and the spatial distribution of schools in the municipality of Vagos

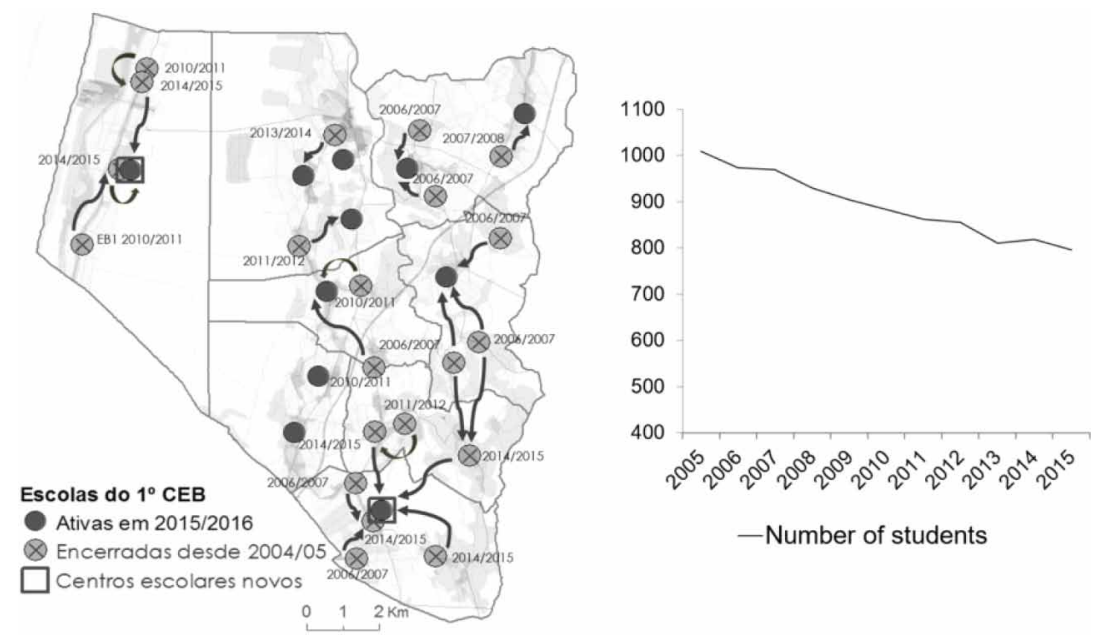

Source: (Authors own elaboration, based on data provided by the municipality)

analyses of this phenomenon can be found in Cordeiro and Martins (2012) and Cordeiro et al. (2014), or, more recently, in Marques et al. (2020).

\section{Data and Methods}

It is hard to assume that schools in a municipality are planned from the beginning. Therefore, creating mathematical models for optimizing school locations is a rough abstraction and can be seen as an oversimplification. But models can be used to analyze the current system and propose changes that correspond to desired policy goals (Giesen, Oliveira, \& Marianov, 2015). Linear programs are no exception, being vastly used in public service provisioning, and namely facility location problems (Drezner \& Hamacher, 2002; ReVelle \& Eiselt, 2005). For school location, this has been done by several authors. Bruno, Genovese, Piccolo, and Sterle (2014), for example, modeled a similar trade-off between cost efficiency and equity in school accessibility in an Italian region. Chen, Thill, and Delmelle (2017), created a model based on a p-median problem applied in the United States, focusing on the challenges to include real world constrains. In both cases, the authors used facility location models to find optimal school distributions. Other cases are described by Giesen et al. (2015), analyzing the challenges of rural school location in Brazil, including a survey of different applications of school sizing and locations problems, and Dai, Wang, Zhang, Liao, and Liu, (2019), who analyze the impact of school consolidation on students' travel time. This last work is particularly interesting, given its focus on school closures, which will be a dominant feature in school planning in many regions in the next decades (and, as noted by ReVelle, Murray, and Serra, 2007, location science has paid little attention to the need to model shrinking services). In Portugal, Antunes and Peeters (2000) and Teixeira and Antunes (2008) have also analyzed school locations based on linear optimization approaches.

While the work presented in this article is not novel in using linear programming for optimal school location, it contributes to this subject by proposing a way to translate broader spatial policy goals into strict parameters. As discussed in the general context section, the size and spatial distribution of schools in Vagos developed over the years, with schools being closed as the number of student dropped. Discussing the implications of these changes, and how they relate to school distributions that minimize inequality in accessibility or expenditure, can thus make important contributions to understanding school planning policies. 
In this work, the spatial distribution that maximizes accessibility was obtained by solving a p-median problem, while the most cost-effective distribution was obtained by solving a capacitated facility location problem, with capacity and school size constraints. The p-median model allocates the demand (students) to the closest facility (school) by minimizing the sum of distances from each student to the closest school (Boloori Arabani \& Alireza, 2012). Although this can generate solutions where some nodes are quite distant from the nearest school, it also tends to minimize the average travel time and, in this study, also minimized the variance of distances, which can be considered a form of spatial equity. A more complex approach is the capacitated location-allocation problem, in which the allocation of the demand to the facilities may be constrained due to the facilities' capacity, costs, or even travel-time (Klose \& Drexl, 2005; Boloori Arabani \& Alireza, 2012).

\section{Investment and Operational Costs of Primary Schools in Portugal}

Regarding primary schools, it is possible to assume efficiency maximizing solutions as the ones that imply the minimum costs for constructing and operating schools, as well as for transportation. As was noted, concentrating students in fewer facilities generally decreases costs due to economies of scale. But how exactly are these costs related to different accessibilities in Portugal?

Probably the most comprehensive assessment of the operational costs of running primary schools in Portugal was made by the Court of Auditors in 2012 (Tribunal de Contas, 2012). This assessment summed up the costs of different budget headings (namely from municipalities and the Education Ministry), excluding only investment costs and the amortization of real estate. As can be seen in Figure 4, this data shows a strong correlation between the average size of primary schools in a NUTS 3 (the smallest geographical unit for which this data was available) and the average cost per student.

For assessing investment costs, the contracts for the construction of fourteen primary schools were analyzed. The considered contracts were those that were signed after 2010, that were available online, and that specified the number of students for which the schools were projected as well as their construction costs. As can be seen in Figure 4, construction costs increase linearly with size but have a high constant, which means that concentrating students in fewer facilities also decreases investment costs.

Three different school sizes where considered: 21 (the minimum defined by the law, Resolução do Conselho de Ministros $n^{\circ}$ 44/2010), 80 (the number of students considered necessary for their good functioning according to national planning guidelines; DGOTDU, 2002), and 225 (the maximum size considered as adequate by the DGOTDU is 300 , but would be exaggerated for the predominantly rural context of Vagos). The construction and operation costs for each of these sizes were obtained

Figure 4. Average cost per student per NUTS 3 (v. 2002) in 2009/2010 by average school size and construction costs for fourteen primary schools in Portugal, from 2010-2019, by size
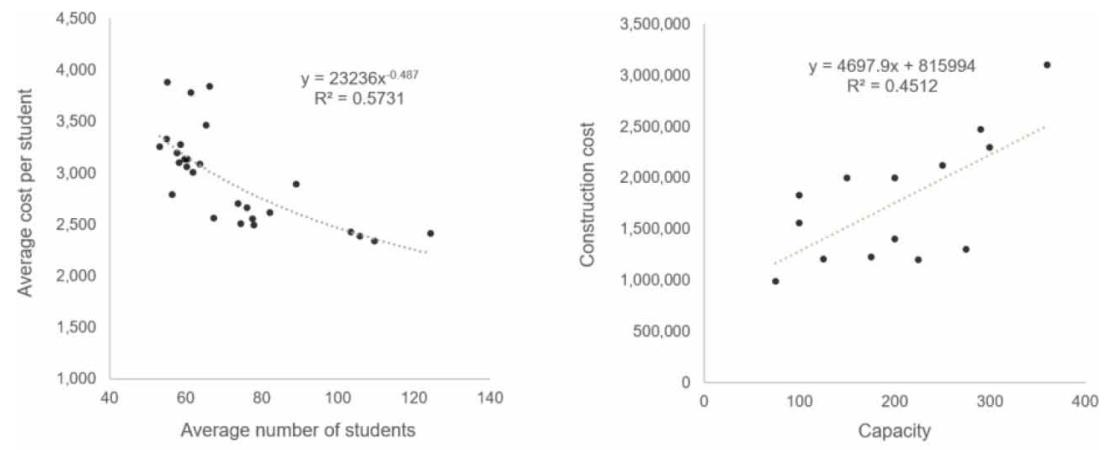

Source: (Tribunal de Contas, 2012) 
Table 1. Construction and operational costs for different school sizes

\begin{tabular}{|l|l|l|}
\hline \multicolumn{1}{|c|}{ Size } & \multicolumn{1}{|c|}{ Construction Costs $(€)$} & \multicolumn{1}{c|}{ Operational Cost per Student $(€)$} \\
\hline 21 students & 914650 & 5275 \\
\hline 80 students & 1191826 & 2750 \\
\hline 225 students & 1873022 & 1662 \\
\hline
\end{tabular}

by using the function with the best fit (linear for construction and log linear for operational costs) and vary considerable for each size, as can be seen in Table 1 .

\section{Student Location and Transportation Costs}

Transportation costs, on the contrary, increase with school closures, given that fewer facilities imply greater distances to be covered by the students. For getting transportation costs the following formula was used:

\section{Transportationcost $=2 * D^{*} 0.36 € * 180$ days $* 10$ years}

where $D$ is the distance to be covered by the students to the nearest school and an average cost of $0.36 €$ is considered per kilometer, according to the travel expenses which the public sector uses for employees who use private transportation in official duty (Decreto-Lei n. ${ }^{\circ} 137 / 2010,2010$ ). It is also assumed that students go to school on 180 days a year and make the journey twice a day. The whole costs where estimated for a ten-year period which, as previously noted, is the time frame for which the local planning instruments are made and after which they must be reviewed.

Although the exact location of the students throughout the territory is not known, it is possible to get a very good estimate by taking the population in the relevant age-group and applying the enrolment rate (in Vagos, the enrolment rate in 2011 was 97\%). The most disaggregated spatial level for which population data is available in Portugal is the statistical subsection, and thus the distance from the centroid of each subsection to the nearest facility was used. To estimate distances and travel costs, a distance matrix was created taking the subsections' centroids as origins (students demand) and destinations (schools offer) using a geodesic distance algorithm from Geopy library.

\section{Location-Allocation Models}

As was previously mentioned, equity maximizing distributions of schools were obtained through a p-median model minimizing travel costs while retaining the actual number of schools. This allows to understand how the current distribution, which is the outcome of different policy decisions over the years, performs regarding equity standards.

The model can be formulated as:

Minimize: $\sum_{i=1}^{n} \sum_{j=1}^{m} c_{i j} x_{i j}$

subject to: $\sum_{j=1}^{m} x_{i j}=1$ for $i=1, \ldots, n \sum_{j=1}^{m} y_{j}=p$

$x_{i j} \leq y_{j}$ for $i=1, \ldots, n ; j=1, \ldots, m x_{i j} \in\{0,1\}$ for $i=1, \ldots, n ; j=1, \ldots, m y_{j} \in\{0,1\}$

for $j=1, \ldots, n$ 
where $i$ is an index in the demand network and $j$ is an index of the potential location of a facility, $x_{i}$ is the demand fraction of node $i$ and $c_{i j}$ is the distance cost from node $i$ to the site of a potential facility $j . p$ is the number of facilities to be located. The decision variables are $X_{i j}$ to calculate the fraction of students from subsection $i$ allocated to a school at site $j$ and $Y_{i}=1$, if the site $j$ will have a school (facility) or not. As can be seen in the specification, the algorithm minimizes the sum of distances from each demand point (students) to the closest facility (school), regardless of the costs of providing the facilities. Nevertheless, later the costs were added, based on the number of students allocated to each school following the expression in Figure 4.

For maximizing efficiency, a capacitated facility location model was used, with the following formulation:

Minimize: $\sum_{j=1}^{m} f_{j} y_{j}+\sum_{i=1}^{n} \sum_{j=1}^{m} c_{i j} x_{i j}$

subject to:

$\sum_{j=1}^{m} x_{i j}=d_{i}$, for $i=1, \ldots, n \sum_{j=1}^{m} x_{i j} \leq M_{j} y_{j}$, for $j=1, \ldots, m$

$x_{i j} \leq d_{i} y_{j}$, for $i=1, \ldots, n ; j=1, \ldots, \mathrm{m}$

$x_{i j} \geq 0$, for $i=1, \ldots, n ; j=1, \ldots, \mathrm{m}$

$y_{j} \in\{0,1\}$ for $j=1, \ldots, \mathrm{m}$

where $i$ is the subsection $d_{i}$ is the demand of students of this subsection and $j$ is a potential facility (school) site, the same as in the previous formula. The decision variables still are the continuous $X_{i j}$ and the binary $Y_{i}$ meaning the correspondent fraction of students allocated to some site and if the potential school will be built, respectively. The installation cost of a school $j$ is also considered to be optimized if the school is activated $f_{j} y_{j}$. The first constraint requires that the demand (number of students) of every subsection must be satisfied, while the second constraint ensures that the school capacity is observed: if the school is activated $\left(y_{j}=1\right)$, its capacity is restricted to $M_{j}$ if it is not activated $\left(y_{j}=0\right)$, the number of students allocated in the school $j$ is zero. The third constraint was implemented to provide variable upper bounds, providing a tighter linear programming relaxation. A slight modification from the default capacity facility location model is made in the third constraint regarding the programming code, in order to allow the model to receive different schools sizes at the same site and still decide for only one school per subsection. The last two constraints define the boundaries of the decision variables. This model was solved using the Python library Gurobi (Gurobi Optimization, 2020).

\section{Outcomes}

Applying the two models yields the outcomes in Figure 5. As can be seen, the capacitated facilitylocation leads to a concentration of all the students in only four facilities, all of which have the maximum capacity that was allowed by the model. Solving the p-median problem, as would be expected, leads to schools being distributed throughout the territory.

The concentration of school facilities, as modeled by the capacitated facility location algorithm, would imply a substantial reduction in the total costs. This is due to the lower operational costs, which weight heavier on the total costs than the investment for building new facilities or transportation costs (Table 2). In short, the outcomes show that school closure and the concentration of students in larger 
Figure 5. Actual school distribution, in 2015, and distribution resulting from applying p-median and capacitated facility location algorithms
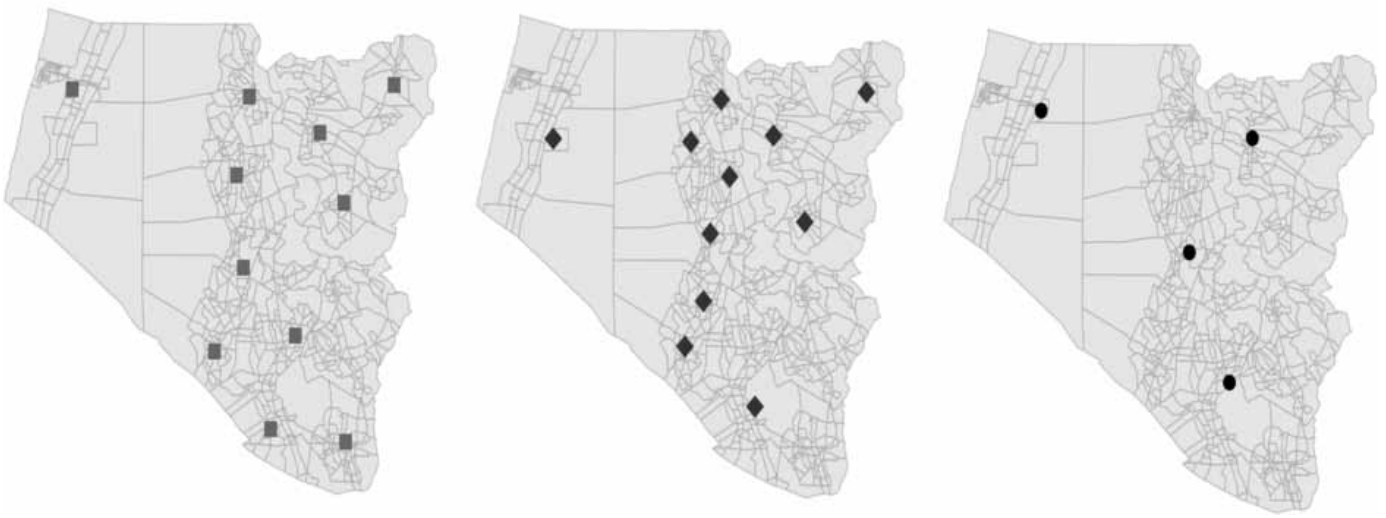

Table 2. Cost of the different spatial distributions of schools

\begin{tabular}{|l|l|l|l|l|}
\hline \multicolumn{1}{|c|}{ Costs $(€)$} & \multicolumn{1}{|c|}{ Investment } & Operational Costs & \multicolumn{1}{c|}{$\begin{array}{c}\text { Transportation } \\
\text { Costs }\end{array}$} & \multicolumn{1}{c|}{ Total } \\
\hline P-median facility location & 13128878 & 23622726 & 1284358 & 38035961 \\
\hline Real location & 12715462 & 22128309 & 1652561 & 36496333 \\
\hline Capacitated facility location & 7492086 & 14819729 & 3199627 & 25511442 \\
\hline
\end{tabular}

facilities is, in fact, the best course to follow from an efficiency perspective, as has been assumed by the rationalizing goal of many of the central government guidelines. But what are be the implications of this type of strategy from an equity perspective?

Interestingly, the coefficient of variation of the distance from the places of residence of the students to the school to which they are allocated is lowest when solving the capacitated facility location problem (Table 3). This basically means that, when controlling for the average distance of the different spatial layouts, the capacitated facility location has the lowest variability in the accessibility to primary schools. A similar idea emerges from the Lorenz curve of the distances covered by the students in Figure 6. This figure shows that the curve for the capacitated facility location is less unequal than the one representing the p-median facility location, even if they are very similar.

But network layouts focused on maximizing accessibility, like the one resulting from solving the p-median location problem, not only provide much lower travel times, but also lower standard

Table 3. Descriptive statistics of the distance $(\mathrm{km})$ of the students to closest school

\begin{tabular}{|l|l|l|l|l|}
\hline \multicolumn{1}{|c|}{ Distance } & Maximum Value & \multicolumn{1}{|c|}{ Mean } & \multicolumn{1}{c|}{$\begin{array}{c}\text { Standard } \\
\text { Deviation }\end{array}$} & $\begin{array}{c}\text { Coefficient of } \\
\text { Variation }\end{array}$ \\
\hline P-median facility location & 4.77 & 1.12 & 0.71 & 0.63 \\
\hline Real location & 5.14 & 1.44 & 0.99 & 0.69 \\
\hline Capacitated facility location & 6.72 & 2.79 & 1.56 & 0.56 \\
\hline
\end{tabular}



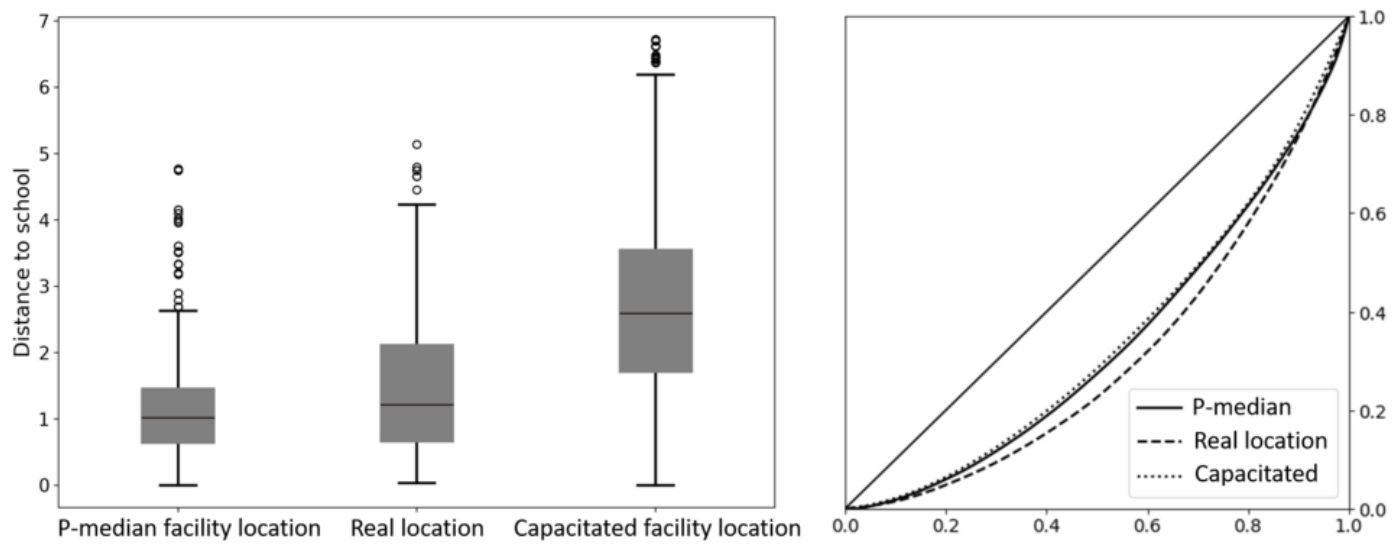

deviations and maximum distances (Table 3). Thus, this spatial distribution is the one that best meets Rawlsian principles of justice, since the differences between the distances covered by the students are smaller and, in particular, the distances covered by the least well-off (those who are furthest from a school) are lower. Decreasing the number of schools would also lead to significant reductions in the number of students that are within a reasonable walking distance, considered to be one kilometer by the spatial planning guidelines provided by the national agency for territory planning (DGOTDU, 2002).

A reduction in the number of schools can, further, negatively affect spatial equity from a capability perspective: The number of students that are within a reasonable distance from the schools decreases significantly when they are concentrated in fewer locations, implying that their choices are significantly reduced. This is particular important since the access to a given school tends to be tied to the place of residence and, therefore, living close to several schools can provide substantial opportunities to members of that community (Burgess et al., 2011). Increasing the distance to a service also leads to a more substantial reduction in capabilities in the disadvantaged groups than in more advantaged ones, given that they tend to have fewer options available to them and tend to depend more on public transportation (Dodson et al., 2010). Further, the benefits of living close to a school are not restricted to families with school-aged children, since housing prices tend to be higher in areas with better schools, in effect meaning the capitalization of an excludable public good into housing values (Brunner et al., 2012).

But the actual spatial distribution of schools in Vagos, while having witnessed a significant decrease in the number of schools in the last decades, is still very far from efficiency maximizing solutions. In other words, the closure of primary schools was made in a way that a high level of spatial accessibility was maintained throughout the territory: The p-median has only slightly lower maximum and average values regarding the distance covered by the students. The costs for the two solutions are also very similar, with the outcomes of the p-median facility location problem having marginally lower operational costs and higher transportation costs.

\section{CONCLUSION}

What can be learned from using a capacitated facility location and p-median facility location problem to generate hypothetical planning solutions? A first major contribution is showing that, as was noted in the literature, costs can be decreased by operating fewer schools (Ares Abalde, 2014; Chakraborty et al., 2000), even when considering increased transportation costs. In other words, from an efficiency 
perspective it makes sense to close as many schools as possible, as tends to be assumed by the central state's regulations on school planning.

The analysis also showed that this concentration would raise important equity concerns, increasing the travel time on average and, in particular, for those who are furthest from a school. As was noted in the previous point, school closures also decrease the number of choices. Thus, a concentrated network can be considered to pose some challenges from an equity perspective, according to a Rawlsian as well as a capability perspective. Nonetheless, the fact that the solution generated by the capacitated facility location has a lower variation of the distances to the nearest school when controlling for scale, also shows the difficulty in finding unique criteria to judge the justice of the spatial planning solutions (this difficulty was already noted by Israel and Frenkel, 2018, or Pereira, Schwanen, and Banister, 2017).

But the most important contribution of this article is that it illustrates how the trade-off between efficiency and equity can be modelled, and the outcomes of different algorithms used as benchmarks to assess actual spatial configurations. It allows, for example, to conclude that changes in the spatial distribution in the analyzed municipality were made with significant equity concerns. In fact, the new spatial distribution guarantees high levels of accessibility in the different parts of the territory - to the point where an equity maximizing solution would not differ significantly from it. It also allows to show the implications that a further school closure would have in terms of increased travel times, as well as regarding the spatial equity in accessibilities.

Notwithstanding, there are also some limitations which are worth discussing. First, the estimated costs for construction and transportation could be subject to a more detailed analysis. The construction costs, for example, vary significantly according to different regions and different locations. In more urbanized areas, higher real estate prices will lead to investment costs having a larger weight than in more rural areas, where the more dispersed settlement structures will lead to higher travels costs. Second, travel costs were estimated individually and not differentiated by mode of transportation. It would be useful to consider public transportation costs, although this would pose some difficulties given that the routes change frequently to adapt to changing demand. It would further be interesting to analyze the impact of different school distributions on the possibility of students to reach the school walking and to take into consideration the opportunity costs of commuting. Third, the definition of equity as maximizing accessibility is, of course, a significant simplification. As was acknowledged, equity in the access to primary schools can be assessed in many different forms, ranging from student performance to the capacity of different students or socioeconomic groups to overcome this distance. An interesting contribution to a broader analysis of equity in the accessibility to primary schools could be to consider citizens' preferences regarding school configurations or the weight of different users' travel costs. This could lead to an approach that includes a broader perception of quality of life, and the advantage that different groups get from the accessibility to schools. Fourth, actual road travel time could be used instead of geodesic distances, even if this is unlikely to produce major changes, given the municipalities dense road network.

\section{ACKNOWLEDGMENT}

This work is the output of the research of two projects: SPLACH - Spatial PLanning for CHange (POCI-01-145-FEDER-16431) and DRIVIT-UP - DRIVIng forces of urban Transformation: assessing pUblic Policies (POCI-01-0145-FEDER-031905). These are supported by the research unit on Governance, Competitiveness and Public Policy (GOVCOPP), and funded by FEDER funds through COMPETE 2020 - Programa Operacional Competitividade e Internacionalização (POCI) and by national funds through FCT - Fundação para a Ciência e a Tecnologia. 


\section{REFERENCES}

Alberini, A. (1995). Testing willingness-to-pay models of discrete choice contingent valuation survey data. Land Economics, 71(1), 83-95. doi:10.2307/3146760

Antunes, A., \& Peeters, D. (2000). A dynamic optimization model for school network planning. Socio-Economic Planning Sciences, 34(2), 101-120. doi:10.1016/S0038-0121(99)00014-2

Ares Abalde, M. (2014). School size policies: A literature review. OECD Education Working Paper No. 106. 10.1787/5jxt472ddkjl-en

Arrow, K. J. (1950). A difficulty in the concept of social welfare. Journal of Political Economy, 58(4), 328-346. doi:10.1086/256963

Arrow, K., Solow, R., Portney, P., Leamer, E., Radner, R., \& Schuman, H. (1993). Report of the NOAA panel on contingent valuation. Federal Register, 58(10), 4601-4614.

Autti, O., \& Hyry-Beihammer, E. (2014). School closures in rural Finnish communities. Journal of Research in Rural Education, 29(1), 1-17.

Barakat, B. F. (2015). A 'recipe for depopulation'? School closures and regional population decline in Saxony. Population Space and Place, 21(8), 735-753. doi:10.1002/psp.1853

Barroso, J. (2013). A emergência do local e os novos modos de regulação das políticas educativas. Educação. Temas e Problemas, 12/13, 13-25.

Bellinger, W. (2007). The Economic Analysis of Public Policy. Routledge., doi:10.4324/9780203946480

Boloori Arabani, A., \& Farahani, R. Z. (2012). Facility location dynamics: An overview of classifications and applications. Computers \& Industrial Engineering, 62(1), 408-420. doi:10.1016/j.cie.2011.09.018

Bromley, D. W. (1990). The ideology of efficiency: Searching for a theory of policy analysis. Journal of Environmental Economics and Management, 19(1), 86-107. doi:10.1016/0095-0696(90)90062-4

Brummet, Q. (2014). The effect of school closings on student achievement. Journal of Public Economics, 119, 108-124. doi:10.1016/j.jpubeco.2014.06.010

Brunner, E. J., Cho, S. W., \& Reback, R. (2012). Mobility, housing markets, and schools: Estimating the effects of inter-district choice programs. Journal of Public Economics, 96(7-8), 604-614. doi:10.1016/j. jpubeco.2012.04.002

Bruno, G., Genovese, A., Piccolo, C., \& Sterle, C. (2014). A Location Model for the Reorganization of a School System: The Italian Case Study. Procedia: Social and Behavioral Sciences, 108, 96-105. doi:10.1016/j. sbspro.2013.12.823

Burgess, S., Greaves, E., Vignoles, A., \& Wilson, D. (2011). Parental choice of primary school in England: What types of school do different types of family really have available to them? Policy Studies, 32(5), $531-547$. doi:10.1080/01442872.2011.601215

Câmara Municipal de Vagos. (2015). Plano Estratégico Municipal. Author.

CCDRC (2013), Plano de Ação Regional 2014-2020. Competitividade Responsável, Estruturante e Resiliente - CRER 2020: Mobilização, Envolvimento, Trabalho em Rede, Ambição, Solidariedade. Versão de Trabalho.

Chakraborty, K., Biswas, B., \& Lewis, W. C. (2000). Economies of scale in public education: An econometric analysis. Contemporary Economic Policy, 18(2), 238-247. doi:10.1111/j.1465-7287.2000.tb00021.x

Chang, H. S., \& Liao, C. H. (2011). Exploring an integrated method for measuring the relative spatial equity in public facilities in the context of urban parks. Cities (London, England), 28(5), 361-371. doi:10.1016/j. cities.2011.04.002

Chen, M., Thill, J.-C., \& Delmelle, E. (2018). iGLASS: An Open Source SDSS for Public School LocationAllocation. In J. Thill \& S. Dragicevic (Eds.), GeoComputational Analysis and Modeling of Regional Systems. Advances in Geographic Information Science (pp. 325-353). Springer. 
Cohn, E. (1968). Economies of scale in Iowa high school operations. The Journal of Human Resources, 3(4), 422-434. doi:10.2307/144795

Cordeiro, A. M. R., \& Martins, H. A. (2012). A Carta Educativa Municipal como instrumento estratégico de reorganização da rede educativa: Tendências de mudança. Caderno de Geografia, 30/31, 339-356. doi:10.14195/0871-1623_32_28

Cordeiro, A. M. R., Martins, H. A., \& Ferreira, A. G. (2014). As cartas educativas municipais e o reordenamento da rede escolar no Centro de Portugal: Das condições demográficas às decisões políticas. Ensaio: Avaliação $e$ Políticas Públicas Em Educação, 22(84), 581-607. doi:10.1590/S0104-40362014000300002

Davoudi, S., Wishardt, M., \& Strange, I. (2010). The ageing of Europe: Demographic scenarios of Europe's futures. Futures, 42(8), 794-803. doi:10.1016/j.futures.2010.04.011

Dai, T., Wang, L., Zhang, Y., Liao, C., \& Liu, Z. (2019). The cost of school consolidation policy: Implications from decomposing school commuting distances in Yanqing, Beijing. Applied Spatial Analysis and Policy, 12(2), 191-204.

Decreto-Lei n.o 21/2019. D.R. I Série. 21 (2019/05/30) § (2019).

DGOTDU. (2002). Normas para Programação e Caracterização de Equipamentos Coletivos. DGOTDU.

Drezner, Z., \& Hamacher, H. W. (2002). Facility location: applications and theory. Facility Location Application and Theory. Retrieved from https://www.amazon.co.uk/Facility-Location-Applications-Zvi-Drezner/ $\mathrm{dp} / 3540213457$

Dodson, J., Burke, M., Evans, R., Gleeson, B., \& Sipe, N. (2010). Travel behavior patterns of different socially disadvantaged groups: Analysis of household travel survey data for a dispersed metropolitan area. Transportation Research Record: Journal of the Transportation Research Board, 2163(1), 24-31. doi:10.3141/2163-03

Egelund, N., \& Laustsen, H. (2006). School closure: What are the consequences for the local society? Scandinavian Journal of Educational Research, 50(4), 429-439. doi:10.1080/00313830600823787

Elshof, H., Haartsen, T., \& Mulder, C. H. (2015). The effect of primary school absence and closure on inward and outward flows of families. Tijdschrift voor Economische en Sociale Geografie, 106(5), 625-635. doi:10.1111/ tesg. 12172

Fainstein, S. S. (2009). Spatial justice and planning. Justice Spatiale/Spatial Justice, 1, 1-13. 10.1002/9781119084679.ch13

Frenkel, A., \& Israel, E. (2018). Spatial inequality in the context of city-suburb cleavages: Enlarging the framework of well-being and social inequality. Landscape and Urban Planning, 177, 328-339. doi:10.1016/j. landurbplan.2017.02.018

Giesen, R., Oliveira, P. R. E., \& Marianov, V. (2015). Rural school location and student allocation. In Applications of Location Analysis (pp. 273-289). Springer., doi:10.1007/978-3-319-20282-2_11

Gurobi Optimization, L. L. C. (2020). Gurobi Optimizer Reference Manual. Retrieved from http://www.gurobi. com

Israel, E., \& Frenkel, A. (2018). Social justice and spatial inequality: Toward a conceptual framework. Progress in Human Geography, 42(5), 647-665. doi:10.1177/0309132517702969

Jordan, B. (2008). Welfare and Well-being: Social Value in Public Policy. Policy Press., doi:10.2307/j.ctt9qgp36

Just, R. E., Hueth, D. L., \& Schmitz, A. (2004). The Welfare Economics of Public Policy. Edward Elgar Publishing Limited.

Kearns, R. A., Lewis, N., McCreanor, T., \& Witten, K. (2009). "The status quo is not an option": Community impacts of school closure in South Taranaki, New Zealand. Journal of Rural Studies, 25(1), 131-140. doi:10.1016/j.jrurstud.2008.08.002

Klose, A., \& Drexl, A. (2005). Facility location models for distribution system design. European Journal of Operational Research, 161(1), 4-29. doi:10.1016/j.ejor.2003.10.031 
Knudsen, J. K., Wold, L. C., Aas, Ø., Kielland Haug, J. J., Batel, S., Devine-Wright, P., Qvenild, M., \& Jacobsen, G. B. (2015). Local perceptions of opportunities for engagement and procedural justice in electricity transmission grid projects in Norway and the UK. Land Use Policy, 48, 299-308. doi:10.1016/j.landusepol.2015.04.031

Kunzmann, K. R. (1998). Planning for spatial equity in Europe. International Planning Studies, 3(1), 101-120. doi:10.1080/13563479808721701

Lang, T. (2012). Shrinkage, metropolization and peripheralization in East Germany. European Planning Studies, 20(10), 1747-1754. doi:10.1080/09654313.2012.713336

Le Grand, J. (1990). Equity versus efficiency: The elusive trade-off. Ethics, 100(3), 554-568. doi:10.1086/293210

Lourenço Marques, J., Tufail, M., Wolf, J., \& Madaleno, M. (2020). Population growth and the local provision of services: The role of primary schools in Portugal. Population Research and Policy Review, 00(00). Advance online publication. doi:10.1007/s11113-020-09573-z

Lyson, T. A. (2002). What does a school mean to a community? Assessing the social and economic benefits of schools to rural villages in New York. Journal of Research in Rural Education, 17, 131-137. doi:10.1007/ s10680-013-9309-2

Machado, R., \& Azevedo, A. (2020). Determinants and Consequences of Citizens' E-Participation: The Case Study of the App MyHomeCity. International Journal of E-Planning Research, 9(1), 20-43. doi:10.4018/ IJEPR.2020010102

Ministério das finanças e da administração pública. Decreto-Lei n.o 137/2010, D.R. I Série. 250 (2010/12/28) $\S(2010)$.

Morrill, R. L., \& Symons, J. (1977). Efficiency and equity aspects of optimum location. Geographical Analysis, 9(3), 215-225. doi:10.1111/j.1538-4632.1977.tb00575.x

Nylund, K. (2014). Conceptions of justice in the planning of the new urban landscape - Recent changes in the comprehensive planning discourse in Malmö, Sweden. Planning Theory \& Practice, 15(1), 41-61. doi:10.108 $0 / 14649357.2013 .866263$

Oppenheimer, J. (2012). Principles of Politics. Cambridge University Press., doi:10.1017/CBO9781139053334

Pereira, R. H. M., Schwanen, T., \& Banister, D. (2017). Distributive justice and equity in transportation. Transport Reviews, 37(2), 170-191. doi:10.1080/01441647.2016.1257660

Pinho, M., \& Botelho, A. (2018). Inference procedures to quantify the efficiency-equality trade-off in health from stated preferences: A case study in Portugal. Applied Health Economics and Health Policy, 16(4), $503-513$. doi:10.1007/s40258-018-0394-6 PMID:29675693

Rawls, J. (1971). A Theory of Justice. Harvard University Press.

Rawls, J. (1981). The basic liberties and their priority. Tanner Lectures on Human Values, 3-87.

Resolução do Conselho de Ministros n.o 44/2010, D.R.I Série. 113 (2010/06/14) § (2010).

Sen, A. (1992). Inequality Reexamined. Harvard University Press.

Sen, A. (2009). The Idea of Justice. The Belknap Press of Harvard University Press. doi:10.2307/j.ctvjnrv7n

ReVelle, C., Murray, A. T., \& Serra, D. (2007). Location models for ceding market share and shrinking services. Omega, 35(5), 533-540. doi:10.1016/j.omega.2005.10.001

ReVelle, C. S., \& Eiselt, H. A. (2005). Location analysis: A synthesis and survey. European Journal of Operational Research, 165(1), 1-19. doi:10.1016/j.ejor.2003.11.032

Silva, C. N. (2010). The e-planning paradigm - Theory, methods and tools: An overview. In Handbook of research on e-planning: ICTs for urban development and monitoring (pp. 1-14). IGI Global., doi:10.4018/9781-61520-929-3.ch001

Slee, B., \& Miller, D. (2015). School closures as a driver of rural decline in Scotland: A problem in pursuit of some evidence? Scottish Geographical Journal, 131(2), 78-97. doi:10.1080/14702541.2014.988288 
Somarakis, G., \& Stratigea, A. (2019). Guiding informed choices on participation tools in spatial planning: An e-decision support system. International Journal of E-Planning Research, 8(3), 38-61. doi:10.4018/ IJEPR.2019070103

Taleai, M., Sliuzas, R., \& Flacke, J. (2014). An integrated framework to evaluate the equity of urban public facilities using spatial multi-criteria analysis. Cities, 40(PA), 56-69. .10.1016/j.cities.2014.04.006

Teixeira, J. C., \& Antunes, A. P. (2008). A hierarchical location model for public facility planning. European Journal of Operational Research, 185(1), 92-104. doi:10.1016/j.ejor.2006.12.027

Tribunal de Contas. (2012). Apuramento do custo médio por aluno. Author.

Tsou, K. W., Hung, Y. T., \& Chang, Y. L. (2005). An accessibility-based integrated measure of relative spatial equity in urban public facilities. Cities (London, England), 22(6), 424-435. doi:10.1016/j.cities.2005.07.004

Wiechmann, T., \& Pallagst, K. M. (2012). Urban shrinkage in Germany and the USA: A comparison of transformation patterns and local strategies. International Journal of Urban and Regional Research, 36(2), 261-280. doi:10.1111/j.1468-2427.2011.01095.x PMID:22518884

Wolf, J., Nogueira, F., \& Borges, M. (2020). A collaborative methodology for local strategic planning: Insights from four plans in Portugal. Planning Practice and Research, OO(00), 1-17. doi:10.1080/02697459.2020.1755138

Wolf, J., Borges, M., Marques, J. L., \& Castro, E. (2019). Smarter decisions for smarter cities: Lessons learned from strategic plans. In L. C. Carvalho, C. Rego, M. R. Lucas, M. I. Sánchez-Hernández, \& A. B. N. Viana (Eds.), New Paths of Entrepreneurship Development (pp. 7-30)., doi:10.1007/978-3-319-96032-6_2

Jan Wolf has a master degree in Regional and Urban Planning from the University of Aveiro and a degree in Sociology from the University of the Beira Interior. He is currently a PhD student in the Doctoral Program of Public Policy of the University of Aveiro, with a research grant from the FCT (Portuguese Science Foundation). He is a Research fellow in the GETIN_UA - Research Group in Territory and Innovation - since 2010 and member of the decision support systems group of the GOVCOPP - Research Unit for Governance, Competitiveness and Public Policy of the University of Aveiro - since 2014. His research activity has involved the participation in strategic planning projects at regional and local levels, as well as the development of decision support methodologies and tools. His current focus is the demographic evolution and its relations with the planning of public services.

Fillipe Feitosa is a Software Engineer from Universidade de Brasilia, Brazil. Worked with machine learning techniques in LADES (security and dependability laboratory - UnB, Brazil) from 2015 to 2017. Nowadays he is a research fellow member of GETIN_UA, research group in Territory and Innovation, PhD student in Public Policies Doctoral Program. Interested on data science and its applications on urban planning, dynamics and systems.

João Lourenço Marques is assistant professor at the Department of Social, Political and Territorial Sciences of the University of Aveiro, lecturing courses in the areas of Urban and Regional Planning (in the field of quantitative methods and techniques to support decision making). He received his PhD degree in Social Sciences from the University of Aveiro (European PhD), after the MsC in Innovation and Regional Development Policies, and his graduation studies in Urban and Regional Planning by the same university. He was visiting researcher in three Scottish Universities: St Andrews, Dundee and Heriot-Watt (Edinburgh). Currently he is member of the research group on Planning and Innovation (GETIN_UA: https://www.ua.pt/getin_ua/). He is also member of the Research Unit in Governance, Competitiveness and Public Policies (GOVCOPP: https://www.ua.pt/govcopp), coordinating the Research Group of Systems for Decision Support - GOVCOPP. 